\title{
Relação entre o consumo de micronutrientes e distúrbios hidroeletrolíticos em pacientes renais em hemodiálise
}

\author{
Relationship between micronutriente consumption and hydroelectrolytic disorders in renal patients \\ undergoing hemodialysis
}

Relación entre el consumo de micronutrientes y los trastornos hidroelectrolíticos em pacientes renales em hemodiálisis

\section{Resumo}

Objetivo: Avaliar a relação entre distúrbios hidroeletrolíticos e o consumo de cálcio, potássio e fósforo em pacientes renais crônicos durante tratamento hemodialítico. Metodologia: Trata-se de um estudo observacional, de corte transversal, composto por 33 participantes realizado em uma clínica de nefrologia em Fortaleza, executado entre setembro e outubro de 2018. Os dados dos hábitos alimentares foram coletados por meio da aplicação de Questionário de Frequência Alimentar e os valores obtidos em gramatura foram divididos de acordo com a periodicidade do consumo a fim da obtenção de valores diários. Os níveis séricos de cálcio, potássio e fósforo foram obtidos por meio de consulta aos prontuários. Resultados: Média do consumo de cálcio de $641,8 \mathrm{mg}$, potássio 2652,9mg, fósforo $1429,0 \mathrm{mg}$ onde o consumo de cálcio e potássio obtiveram maior adequação e fósforo menor adequação aos padrões de referência. Já os níveis séricos encontrados foi de $8,8 \mathrm{mg} / \mathrm{dL}$ para cálcio, $5,5 \mathrm{mg} / \mathrm{dL}$ para o potássio e fósforo de $5,1 \mathrm{mg} / \mathrm{dL}$. Não houve suficiência na correlação estatística entre consumo e níveis séricos Conclusão: O consumo inadequado de fósforo, além da concentração sérica desajustada deste, conferiram achados relevantes na atual pesquisa. $\mathrm{O}$ uso de quelantes e a metodologia empregada para mensuração do consumo de nutrientes parece interferir em resultados relatados de consumo alimentar, associado a isso, o controle da ingestão deve ser rigorosamente monitorado.

Palavras-chave: Insuficiência renal crônica; Diálise renal; Eletrólitos; Ingestão de alimentos; Micronutrientes.

\footnotetext{
Abstract

Objective: To evaluate the relationship between hydroelectrolytic disorders and the consumption of calcium, potassium and phosphorus in chronic renal patients during hemodialysis. Methods: This is an observational, crosssectional study, composed of 33 participants conducted at a nephrology clinic in Fortaleza, carried out between
} 
September and October 2018. Data on eating habits were collected through the application of the Frequency Questionnaire Food and values obtained by weight were divided according to the frequency of consumption in order to obtain daily values. The serum levels of calcium, potassium and phosphorus were obtained by consulting the medical records. Results: Average calcium intake of $641.8 \mathrm{mg}$, potassium $2652.9 \mathrm{mg}$, phosphorus $1429.0 \mathrm{mg}$ where calcium and potassium consumption achieved greater adequacy and phosphorus less adequacy to reference standards. The serum levels found were $8.8 \mathrm{mg} / \mathrm{dL}$ for calcium, $5.5 \mathrm{mg} / \mathrm{dL}$ for potassium and phosphorus of $5.1 \mathrm{mg} / \mathrm{dL}$. There was no sufficiency in the statistical correlation between consumption and serum levels Conclusion: Inadequate phosphorus consumption, in addition to its inadequate serum concentration, conferred relevant findings in the current research. The use of chelators and the methodology used to measure the consumption of nutrients seems to interfere with reported results of food consumption, associated with this, the control of intake must be strictly monitored.

Keywords: Renal insufficiency chronic; Renal dialysis; Electrolytes; Eating; Micronutrients.

\section{Resumen}

Objetivo: Evaluar la relación entre los trastornos hidroelectrolíticos y el consumo de calcio, potasio y fósforo en pacientes renales crónicos durante hemodiálisis. Metodología: Se trata de un estudio observacional, transversal, compuesto por 33 participantes realizado en una clínica de nefrología en Fortaleza, realizado entre septiembre y octubre de 2018. Los datos sobre hábitos alimentarios fueron recolectados mediante la aplicación del Cuestionario de Frecuencia Alimentaria y los valores Los obtenidos en peso se dividieron según la periodicidad de consumo con el fin de obtener valores diarios. Los niveles séricos de calcio, potasio y fósforo se obtuvieron consultando la historia clínica. Resultados: Ingesta media de calcio de 641,8 mg, potasio 2652,9 mg, fósforo 1429,0 mg donde el consumo de calcio y potasio logró una mayor adecuación y el fósforo una menor adecuación a los estándares de referencia. Los niveles séricos encontrados fueron de $8,8 \mathrm{mg} / \mathrm{dL}$ de calcio, $5,5 \mathrm{mg} / \mathrm{dL}$ de potasio y fósforo de $5,1 \mathrm{mg} / \mathrm{dL}$. No hubo suficiencia en la correlación estadística entre el consumo y los niveles séricos. Conclusión: El consumo inadecuado de fósforo, además de su concentración sérica inadecuada, confirió hallazgos relevantes en la investigación actual. El uso de quelantes y la metodología empleada para medir el consumo de nutrientes parece interferir en los resultados reportados del consumo de alimentos, asociado a esto, el control de la ingesta debe ser estrictamente monitoreado.

Palabras clave: Insuficiencia renal crónica; Diálisis renal; Electrólitos; Ingestión de alimentos; Micronutrientes.

\section{Introdução}

O distúrbio hidroeletrolítico que acompanha a Doença Renal Crônica (DRC) no paciente submetido à hemodiálise (HD) decorre principalmente devido à perda da função renal, principal órgão relacionado à função de controle de eletrólitos e fluidos corporais. Desse modo, o manejo da desordem requer o cuidadoso controle da acidose metabólica, restabelecimento de fluidos corporais e suporte nutricional eficiente. Do contrário, a permanência do metabolismo alterado dos eletrólitos poderá levar a consequências fatais em curto espaço de tempo Kidney Disease Improving Global Outcomes [KDIGO] (2017); Sesso, Lopes, Thomé, Lugon, Martins (2017); Nascimento, Pachaly, Riella (2013); Vega et al. (2019).

O acúmulo de potássio na corrente sanguínea ocorre devido à perda da capacidade funcional do rim de filtrar o excedente deste mineral. Além disso, a hiperpotassemia também é resultado de outros fatores que não a lesão renal diretamente, como uso de fármacos inibidores da enzima conversora de angiotensina (ECA), ação efetiva da diálise reduzida, baixos níveis séricos de aldosterona e acidose metabólica Hannedouche, Fouque, Joly (2018); Serván, Ruiz (2019).

A desregulação do fósforo e cálcio ocorrem devido à incapacidade do rim, podendo causar a doença óssea renal, caracterizada por níveis anormais de cálcio, fósforo, paratormônio (PTH) e vitamina D. A alteração do fósforo ocorre devido ao hiperparatireoidismo secundário à doença renal onde não é possível ocorrer a fosfatúria em resposta a secreção de paratormônio a partir do rim, já que este encontra-se em disfunção, logo, a hiperfosfatemia surge, levando as taxas de mortalidade por doença renal, principalmente causada pela calcificação de vasos sanguíneos. Torna-se, assim, essencial o controle de fósforo a partir da alimentação, com níveis de consumo reduzidos deste mineral Custódio et al. (2013).

Já o cálcio, sua absorção a partir do intestino começa a ser reduzida de acordo com o dano renal e a uremia presente na doença, fazendo com que o cálcio não consiga se ligar completamente à albumina plasmática. Ainda, dentre os efeitos da doença renal crônica no metabolismo do cálcio, está a resistência à ação do PTH nos ossos, sendo causada devido a hiperfosfatemia, redução de vitamina D e possível redução do número de receptores para o PTH nas células ósseas Porto, Truite, Bucharles, Hauser (2016); do Nascimento, Alvarenga, Andrade, Macedo, de Aguiar (2016). 
Considerando o crescente número de portadores de doença renal crônica em processo hemodialítico e a necessidade de acompanhamento nutricional individualizado em virtude das alterações eletrolíticas, o objetivo deste estudo foi avaliar a relação existente entre os distúrbios hidroeletrolíticos e o consumo de cálcio, potássio e fósforo em pacientes renais crônicos submetidos à hemodiálise.

\section{Metodologia}

\section{Delineamento do estudo}

Trata-se de um estudo observacional de corte transversal, quantitativo, onde foi comparado os valores séricos e de consumo de potássio, cálcio e fósforo em pacientes submetidos a hemodiálise durante três meses de coleta Estrela (2018).

\section{Local do estudo}

Foi realizado em uma clínica de hemodiálise de referência localizada em Fortaleza, Ceará, onde possui formas de atendimento voltadas para o público assistido por meio dos sistemas de saúde público e privado, envolvendo equipes multidisciplinares de cuidado ao paciente com doenças renais. A periodicidade da realização de exames bioquímicos é realizada conforme protocolo estabelecido, com verificação mensal dos valores séricos de potássio, cálcio e fósforo.

\section{Participantes}

Foi realizada entrevista direta com 33 pacientes com diagnóstico de DRC e tendo como terapia de substituição renal a hemodiálise onde estes dialisam três vezes durante a semana com tempo médio de 4 horas por sessão, onde os dados foram coletados através de um único contato pessoal, logo após o consentimento individual.

\section{Critérios de inclusão e exclusão}

Os critérios de inclusão foram: pacientes de ambos os sexos; com idade superior ou igual a 19 anos; com doença renal crônica em tratamento hemodialítico; com boa comunicação verbal e estado de consciência normal. Além disso, foram excluídos pacientes portadores de descompensações hemodinâmicas (trombose, embolias, processos hemorrágicos, choque hemodinâmico); neurológicas (acidente vascular encefálico, Alzheimer, demência) e/ou metabólicas graves (hepatopatias, pancreatites, hipo e hiperparatireoidismo, neoplasias, doenças autoimunes). Condições estas que estejam registradas em prontuário e que possam interferir na coleta de dados bioquímicos e consumo alimentar avaliados.

\section{Entrevista direta}

Ocorreu em um único contato, durante três meses de realização da coleta de dados, durante o processo de HD com escolha aleatória de pacientes, foram coletadas informações sobre perfil social, econômico, escolaridade, tempo de DRC e Terapia de Substituição Renal (TSR) por meio de aplicação de questionário, onde o entrevistador mediava perguntas e contemplava a resposta de acordo com valores pré-estabelecidos em cada item.

\section{Prontuário}

Os dados de potássio, cálcio e fósforo séricos foram coletados por meio do acesso ao prontuário de cada paciente, seguindo as normas para realização de exames da clínica referida, a fim de serem obtidos dados que estabeleçam melhor relação entre consumo e nível sérico. Foram considerados os dados de eletrólitos coletados no mesmo mês de aplicação do questionário de frequência alimentar. 


\section{Questionário de frequência alimentar}

Para avaliar o perfil dietético, foi aplicado um questionário de frequência alimentar (QFA) validado para população enferma e sadia, incluindo pessoas com doença renal crônica Selem et al. (2014), que foi aplicado por parte dos pesquisadores em contato pessoal com os pacientes durante processo hemodialítico em uma única vez.

As porções alimentares relatadas foram divididas entre sua periodicidade de consumo e quantidade de consumo em sete (7) dias durante a semana, quando consumido na semana, 30 dias no mês, quando consumidos mensalmente, 365 dias no ano, quando consumido anualmente ou consumo diário, assim, a fim de obter dados mais próximos da realidade de consumo diário de cada alimento. Em seguida, os alimentos e as quantidades em gramas obtidas foram incluídos na tabela de composição química da Universidade Estadual de Campinas [UNICAMP] (2011). Secundariamente, foi utilizado as tabelas da United States Department of Agriculture [USDA] (2013), e do Instituto Brasileiro de Geografia e Estatística [IBGE] (2011), logo em seguida, foram observados e registrados os valores obtidos de potássio, cálcio e fósforo por meio da análise.

Quanto ao tamanho e gramatura das porções alimentares contidas no QFA utilizado, foi considerado a opção "P" como $25 \%$ a menos da gramatura do tamanho "M", já a porção "G" como $25 \%$ a mais, assim como a porção "GG" como $50 \%$ a mais dos valores da gramatura do tamanho médio.

\section{Análise dos dados}

Os valores obtidos a partir da análise do consumo alimentar foram comparados com os valores preconizados nas recomendações. Martins, Sato e Riella recomendaram um consumo diário de 800 a 1000 mg/dia, 1000 a 3000 mg/dia e $<1000$ $\mathrm{mg}$ /dia para fósforo, potássio e cálcio, respectivamente Martins, Sato, Rella (2013). A partir disso, foi classificado cada valor obtido como consumo elevado, baixo consumo ou adequado.

Para os valores séricos de potássio, cálcio e fósforo, encontrados por meio de consulta a prontuários, foi utilizada como recomendação os pontos de corte de 3,5 a 5,5 mEq/L para potássio Martins (2013). Ainda, 3,5 a 5,5 mg/dL e 8,5 a 10,5 mg/dL como nível de concentração sérica para o fósforo e cálcio, respectivamente KDIGO (2017).. Logo após análise, o valor obtido foi estabelecido dentre os padrões "acima do recomendado", "abaixo do recomendado" e "adequado".

Os níveis de concentração sérica dos eletrólitos coletados a partir da consulta aos prontuários dos pacientes foram analisados a fim de indicar a prevalência dos distúrbios hidroeletrolíticos na amostra estudada.

\section{Análise estatística}

As variáveis tiveram sua normalidade certificada a partir do teste de Kolmogorov - Smirnov e a análise de frequência foi realizada com base nas características da Estatística Descritiva, utilizando-se de média, mediana e desvio padrão. Além disso, foi utilizado o Coeficiente de Correlação de Pearson para analisar a correlação entre ingestão alimentar de cálcio, potássio e fósforo e as alterações séricas destes. Todas as análises foram feitas por intermédio do software Statistical Package for the Social Sciences (SPSS) versão 22.0.0.0, considerando significativos os valores de $p \leq 0,05$.

\section{Comitê de ética}

A atual pesquisa foi submetida ao Comitê de Ética em Pesquisa envolvendo seres humanos da Universidade de Fortaleza (UNIFOR), aprovado sob o parecer $n^{\circ} 2.889 .404$.

\section{Resultados}

A amostra foi composta por 33 pessoas, contemplando um universo predominantemente masculino $(66,7 \%)$, com idade entre 22 e 80 anos e média de idade de $24 \pm 9$ anos, no qual 27,3\% estão com idade superior ou igual a 60 anos. O tempo 
referido de diagnóstico de DRC variou de 2 meses a 35 anos e o tempo declarado de tratamento hemodialítico situou-se no intervalo entre 2 meses a 30 anos. Em relação ao âmbito socioeconômico, 75,8\% ( $\mathrm{n}=25)$ estavam recebendo tratamento custeado por meio do Sistema Único de Saúde (SUS) e a renda mensal esteve em 42,3\% dos entrevistados entre 1 e 2 salários mínimos (Tabela 1).

Tabela 1. Características socioeconômicas da amostra. Fortaleza-CE, 2019.

\begin{tabular}{|c|c|}
\hline Tabela 1 & Características socioeconômicas da amostra \\
\hline Variáveis & $\begin{array}{c}\text { População } \\
\text { n }=33\end{array}$ \\
\hline \multicolumn{2}{|l|}{ Idade (anos) } \\
\hline (média \pm desvio padrão) & $24 \pm 9$ \\
\hline \multicolumn{2}{|l|}{ Gênero (\%) } \\
\hline Masculino & $66,7 \%$ \\
\hline Feminino & $33,3 \%$ \\
\hline \multicolumn{2}{|l|}{ Estado civil } \\
\hline Solteiro & $36,4 \%$ \\
\hline Casado & $51,5 \%$ \\
\hline Divorciado & $9,1 \%$ \\
\hline Viúvo & - \\
\hline Outro & $3,0 \%$ \\
\hline \multicolumn{2}{|l|}{ Tipo de convênio } \\
\hline Particular & $24,2 \%$ \\
\hline SUS & $75,8 \%$ \\
\hline \multicolumn{2}{|c|}{ Renda mensal (em salários) } \\
\hline$<1$ & $6,1 \%$ \\
\hline$\geq 1 \mathrm{e}<2$ & $42,3 \%$ \\
\hline$\geq 2 \mathrm{e}<3$ & $21,2 \%$ \\
\hline$\geq 3$ & $30,3 \%$ \\
\hline \multicolumn{2}{|l|}{ Escolaridade } \\
\hline Nenhuma & $3,0 \%$ \\
\hline Fund. Incompleto & $15,2 \%$ \\
\hline Fund. Completo & $6,1 \%$ \\
\hline Médio Incompleto & $18,2 \%$ \\
\hline Médio Completo & $21,2 \%$ \\
\hline Superior Incompleto & $12,1 \%$ \\
\hline Superior Completo & $15,2 \%$ \\
\hline Pós-graduação & $9,1 \%$ \\
\hline
\end{tabular}

Abreviações: SUS, Sistema Único de Saúde. Fund, Fundamental. Fonte: Autores.

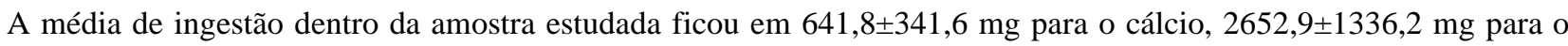
potássio e 1429,0 $\pm 719,5 \mathrm{mg}$ para o fósforo. A partir da classificação do consumo alimentar constatou-se que 75,8\% ( $\mathrm{n}=25)$ dos entrevistados estavam com o consumo deste mineral considerado adequado, enquanto $24,2 \%(\mathrm{n}=8$ ) estavam com o consumo elevado. O potássio consumido por meio da dieta esteve dentro das recomendações em $66,7 \%(\mathrm{n}=22)$ da amostra, ao passo que em 30,3\% ( $\mathrm{n}=10)$ o consumo ficou elevado. Para o fósforo, $66,7 \%$ consumiram acima e $18,2 \%$ abaixo do preconizado pela literatura (Tabela 2). 
Tabela 2. Consumo alimentar de cálcio, potássio e fósforo. Fortaleza-CE, 2019.

\begin{tabular}{lccc} 
Tabela 2 & Consumo alimentar de cálcio, potássio e fósforo & \\
\hline Variáveis & $\mathrm{N}$ & $\%$ & média (DP) \\
Cálcio & 25 & 75,8 & \\
Adequado & 8 & 24,2 & \\
Consumo elevado & & & $2652,9(1336,6)$ \\
Potássio & 1 & 3,0 & \\
Baixo consumo & 22 & 66,7 & $1429,0(719,5)$ \\
Adequado & 10 & 30,3 & \\
Consumo elevado & & & \\
Fósforo & 6 & 18,2 & \\
Baixo consumo & 5 & 15,2 & \\
Adequado & 22 & 66,7 & \\
Consumo elevado & &
\end{tabular}

Fonte: Autores.

A concentração média dos níveis séricos foi de $8,8 \pm 0,6 \mathrm{mg} / \mathrm{dL}$ para o cálcio, $5,5 \pm 0,7 \mathrm{mg} / \mathrm{dL}$ para o potássio e $5,1 \pm$ $1,6 \mathrm{mg} / \mathrm{dL}$ para o fósforo. Quanto à prevalência de distúrbios eletrolíticos, 69,7\% da amostra esteve com a concentração adequada e 27,3\% (n=9) com hipocalcemia. Para o potássio, 63,6\% (n=21) estavam com concentração adequada e 36,4\% (n = 12) apresentaram hipercalemia. O fósforo esteve adequado em 42,4\% $(\mathrm{n}=14)$ dos participantes e acima do recomendado (hiperfosfatemia) em 39,4\% ( $=13)$ (Tabela 3).

Tabela 3. Prevalência de distúrbios hidroeletrolíticos de cálcio, potássio e fósforo. Fortaleza-CE, 2019.

\begin{tabular}{lccc} 
Tabela 3 & Prevalência de distúrbios eletrolíticos de cálcio, potássio e fósforo \\
\hline $\begin{array}{l}\text { Variáveis } \\
\text { Cálcio }\end{array}$ & $n$ & $\%$ & média (DP) \\
Abaixo do recomendado & 9 & 27,3 & $8,8(0,6) \mathrm{mg} / \mathrm{dL}$ \\
$\begin{array}{l}\text { Adequado } \\
\text { Acima do recomendado }\end{array}$ & 23 & 69,7 & \\
Potássio & 1 & 3,0 & $5,5(0,7) \mathrm{mg} / \mathrm{dL}$ \\
Abaixo do recomendado & - & - & \\
Adequado & & & \\
Acima do recomendado & 21 & 63,6 & $5,1(1,6) \mathrm{mg} / \mathrm{dL}$ \\
Fósforo & 12 & 36,4 & \\
Abaixo do recomendado & 6 & 18,2 & \\
Adequado & & 42,4 & \\
Acima do recomendado & 14 & 39,4 & \\
& 13 & & \\
\hline
\end{tabular}

Fonte: Autores.

Os níveis de cálcio, potássio e fósforo obtidos por meio da dieta quando comparados com os distúrbios eletrolíticos de cálcio (hipocalcemia e hipercalcemia), potássio (hipocalemia e hipercalemia) e fósforo (hipofosfatemia e hiperfosfatemia) na amostra estudada não apresentaram correlação significativa, conforme exposto na Tabela 4. 
Tabela 4. Correlação entre consumo alimentar e distúrbios hidroeletrolíticos. Fortaleza-CE, 2019.

\begin{tabular}{|c|c|c|c|c|c|c|}
\hline Tabela 4 & Correlaçã & consur & imentar & túrbios 1 & letrolíti & \\
\hline Consumo alimentar & & & túrbios & oeletrol & & \\
\hline & & & & & & \\
\hline & $\mathrm{r}$ & $\mathrm{p}$ & $\mathrm{r}$ & $\mathrm{p}$ & $\mathrm{r}$ & $\mathrm{p}$ \\
\hline Cálcio & 0,108 & 0,548 & $-0,180$ & 0,316 & 0,183 & 0,309 \\
\hline Potássio & $-0,091$ & 0,616 & $-0,182$ & 0,310 & 0,117 & 0,517 \\
\hline Fósforo & $-0,077$ & 0,671 & $-0,252$ & 0,158 & 0,112 & 0,535 \\
\hline
\end{tabular}

Fonte: Autores.

\section{Discussão}

A população de pacientes renais hemodialíticos no Brasil mostrou variação quanto à idade e ao gênero dos pacientes, conforme encontrado por Luz et al. (2017). Verificou-se que, dos pacientes avaliados no estudo, predominavam mulheres e a idade média era de 55 anos. Nerbass et al. (2018) encontraram prevalência de homens e 46,9 anos de idade média na sua amostra. Para Machado, Bazanelli e Simony (2014), 64,7\% da sua amostra é do gênero masculino, com idade média de 59,4 anos.

A média de consumo de potássio na população brasileira é de 2500mg e está próximo da determinada para pacientes em HD, o que propicia menores dificuldades em controlar a ingestão deste mineral em comparação com o fósforo, como visto por Nerbass e colaboradores (2017), ao analisarem as percepções de pacientes em HD relacionadas às restrições alimentares.

Outro resultado semelhante encontrado por Nerbass et al. (2018), no qual, em comparação ao consumo de fósforo entre dois estados brasileiros, pacientes em HD tanto de Santa Catarina como de Tocantins tiveram consumo elevado do mineral, mostrando que uma possível justificativa vem das preferências alimentares por bebidas e alimentos que contenham elevada quantidade deste micronutriente.

Um trabalho realizado por Rodrigues e outros autores mostrou que, em análise do consumo alimentar, o consumo de cálcio e potássio encontrou-se fora das recomendações em 98,2\% dos pacientes. Em contrapartida, os níveis de ingestão de fósforo estavam adequados na maior parte dos participantes (55,4\%) Rodrigues, Melhem, Cavagnari, Schiessel, Mazu (2017). Apesar do trabalho citado apresentar consumo adequado de proteína entre os partícipes, uma possível explicação do consumo inadequado de cálcio seria devido à ingestão não diária de alimentos do grupo do leite na maior parte da amostra $(78,7 \%)$, achado este que difere do encontrado no presente estudo.

Segundo Machado e Pinhati (2014), onde analisaram o consumo de fósforo e potássio em pacientes com DRC em tratamento hemodialítico através de diário alimentar, constatou que as principais fontes de fósforo ingeridas por estes pacientes eram carne bovina, leite e feijão, e para o potássio, café, feijão e carne bovina. Além disso, foi observada ingestão de fósforo acima do recomendado (50,0\%), semelhante ao atual trabalho. O potássio também teve seu consumo elevado em 58,8\% no estudo citado, contrapondo-se ao encontrado neste trabalho.

Casas, Rodrigues e D'avila (2015) reforçaram a importância da educação relacionada à alimentação para este público, sendo efetivas quando observadas a mudança de comportamento ante a escolhas alimentares, bem como admissão e seguimento de dietas contemplando quantidades de nutrientes adequados.

Os valores séricos de fósforo encontrados por Ferreira e Neves (2013), em sua análise em pacientes com DRC em tratamento hemodialítico, mostram média de $4,56 \mathrm{mg} / \mathrm{dL}$ para homens e $4,65 \mathrm{mg} / \mathrm{dL}$ para mulheres, sendo classificados como 
dentro dos padrões de referência, em comparação com o atual trabalho, que obteve média de $5,1 \mathrm{mg} / \mathrm{dL}$, sem distinção de gênero. Observou-se no presente trabalho $42,4 \%$ de adequação, em contrapartida, encontrou-se $57,6 \%$ de inadequação quando somado hiperfosfatemia e hipofosfatemia.

Ainda, o mesmo estudo resultou a média de cálcio sérico de $9,93 \mathrm{mg} / \mathrm{dL}$ para homens e $9,70 \mathrm{mg} / \mathrm{dL}$ para mulheres, valores considerados adequados segundo a literatura mais recente e que corroboram com os achados do presente estudo $(8,8 \mathrm{mg} / \mathrm{dL})$. Ademais, ambos com elevada prevalência de adequação aos padrões de referência estabelecidos.

$\mathrm{Na} \mathrm{DRC}$, os distúrbios relacionados à homeostase do cálcio estão relacionados à baixa produção de vitamina $\mathrm{D}$ ou a sua ativação que está diretamente relacionada a absorção de cálcio a nível intestinal, ficando esta reduzida.

Alvarenga, Andrade, Moreira, Nascimento, Macedo, Aguiar (2017), em investigação sobre a relação entre tempo de HD e especificações nutricionais, obtiveram médias de $5,57 \mathrm{mEq} / \mathrm{L}$ para potássio sérico, $5,16 \mathrm{mg} / \mathrm{dL}$ para fósforo sérico e 8,89 $\mathrm{mg} / \mathrm{dL}$ para cálcio sérico, com níveis levemente acima do preconizado para o potássio. Assim, confirmando os achados do estudo atual para fósforo e cálcio, com valores dentro do intervalo de normalidade.

Em contrapartida, estudo realizado por Santos, Machado, Pereira, Abreu, Lyra (2013), em sua avaliação bioquímica de pacientes em HD, mostrou que somente 3,3\% dos pacientes obtiveram níveis de cálcio sérico adequados, com 96,7\% encontrados abaixo do recomendado, valores bastante distintos do atual trabalho. Já para o fósforo sérico, 36,7\% encontravamse adequados, valor também inferior ao encontrado.

Foi observado que na relação entre consumo alimentar de cálcio, fósforo e potássio não houve correlação significativa com os níveis séricos destes. Uma possível explicação é a utilização de quelantes de micronutrientes, onde é recomendado quando o cálcio sérico encontra-se abaixo de $9,5 \mathrm{mg} / \mathrm{dL}$ e/ou níveis de fósforo com níveis acima de 5,5mg/dL, de acordo com diretrizes terapêuticas para o tratamento de hiperparatireoidismo secundário em pacientes com DRC, assim, a não investigação do uso de quelantes torna a estimativa do consumo alimentar menos fidedigna Custódio et al. (2013).

A mesma associação foi relatada por Machado et al. (2014) que analisaram a correlação entre consumo e nível sérico de fósforo e potássio e justificam que tal resultado já era esperado devido a fatores envolvendo a atuação efetiva do dialisador e a questões envolvendo a veracidade de informações relatadas por pacientes a respeito de seu consumo alimentar ZadehKalantar, Fouque (2017).

Além disso, a amostra sub-representada de pacientes envolvidos em nosso estudo evidenciou que seria necessário maior número de pessoas a fim de obter maiores variações com relação ao consumo alimentar e valores séricos entre os pacientes, razão pela qual possivelmente não houve estatisticamente relação.

Todavia, o papel da dietoterapia voltada ao controle da ingestão de cálcio, fósforo e potássio é claramente indispensável visto a ineficiência do dialisador na excreção destes micronutrientes, e a associação observada por Telles e Boita (2015) em sua revisão bibliográfica, entre o descontrole de consumo de cálcio, potássio e fósforo combinado aos quadros de hiperparatireoidismo secundário e hipercalemia, pode ocasionar alterações na polarização celular, principalmente células do miocárdio, podendo levar ao óbito Zadeh-Kalantar, Fouque (2017); Serván, Ruiz (2019).

\section{Conclusão}

Este trabalho evidenciou que o consumo alimentar de cálcio e potássio obtiveram maior percentual de adequação quando comparado com as referências padrões e o de fósforo com menor adequação, onde o consumo elevado predominou-se, junto a isso, observou-se concentração sérica de fósforo com maior parte inadequada, além não haver associação entre estes e o tempo TSR, entretanto a educação nutricional e terapia dietética voltada para esse público é insubstituível para prevenção de complicações relacionadas a DRC. 
Sugestões para futuros trabalhos envolvem a análise de quelantes de micronutrientes associado ao consumo alimentar, bem como obtenção de amostra representativa de outros centros de hemodiálise, a fim de melhor caracterização da população estudada.

\section{Referências}

Alvarenga, L. de A., et al (2017). Análise do perfil nutricional de pacientes renais crônicos em hemodiálise em relação ao tempo de tratamento. Brazilian Journal of Nephrology, 39(3), 283-286. https://doi.org/10.5935/0101-2800.20170052.

Casas, J., et al (2015). Educação nutricional para pacientes renais crônicos em programa de hemodiálise. Rev Nutrire, 40(1), 36-44.

Custódio, M. R., C., et al (2013). Protocolo clínico e diretrizes terapêuticas para o tratamento do hiperparatireoidismo secundário em pacientes com doença renal crônica. Brazilian Journal of Nephrology, 35(4), 308-322. https://doi.org/10.5935/0101-2800.20130050.

Do Nascimento, R. P., et al (2016). Relato de experiência: educação alimentar e nutricional com pacientes renais crônicos em hemodiálise. Nutr Clín Diet Hosp, 36(3), 31-7.

Estrela, C. Metodologia científica: ciência, ensino, pesquisa Artes Médicas, 738p.

Ferreira, L. F. S., \& Neves, P. (2013). Aspectos nutricionais de pacientes com doença renal crônica em tratamento de hemodiálise. Rev Bras Nutr Clinic, 28(3), 192-6.

Hannedouche, T., Fouque, D., \& Joly, D. (2018). Complications métaboliques en insuffisance rénale chronique : hyperphosphatémie, hyperkaliémie et anémie [Metabolic complications in chronic kidney disease: hyperphosphatemia, hyperkalemia and anemia]. Nephrologie \& therapeutique, 14(6S), 6S17-6S25. https://doi.org/10.1016/S1769-7255(18)30647-3.

Kidney Disease: Improving Global Outcomes (KDIGO) CKD-MBD Update Work Group (2017). KDIGO 2017 Clinical Practice Guideline update for the diagnosis, evaluation, prevention, and treatment of Chronic Kidney Disease-Mineral and Bone Disorder (CKDMBD). Kidney Int. Suppl, ;7,1-59.

Luz, C. A., et al (2017). Avaliação da ingestão nutricional de pacientes com doença renal crônica em tratamento hemodialítico. Braspen J, 32(3):241-5.

Machado, A. D., et al (2014). Avaliação do consumo alimentar de pacientes com doença renal crônica em hemodiálise. Rev Ci e saúde, mai-ago; 7(2):76-84. https://doi.org/10.15448/1983-652X.2014.2.17758.

Machado, G. R. G., \& Pinhati, F. R. (2014). Tratamento de diálise em pacientes com insuficiência renal crônica. Cad UniFOA, 26:137-48. https://doi.org/10.47385/cadunifoa.v9i26.193.

Martins, C., et al. (2013) Nutrição e HemodiáliseIn: Riella, M. C., Martins, C. Nutrição e o rim (2a ed.). Guanabara Koogan, p149-73.

Martins, C. Padrões de referência para exames laboratoriais. In: Riella MC, Martins C. Nutrição e o rim (2a ed.). Guanabara Koogan; 379-84.

Ministério do Planejamento, Orçamento e Gestão (BR). Instituto Brasileiro de Geografia e Estatística - IGBE (2011). Tabela de Medidas Referidas para os Alimentos Consumidos no Brasil. Rio de Janeiro: Ministério do Planejamento, Orçamento e Gestão. Disponível em: <https://biblioteca.ibge.gov.br/visualizacao/livros/liv50000.pdf>.

Nascimento, M. M., et al Metabolismo de água, sódio, potássio e magnésio na doença renal crônica (2013). In: Riella. M. C., \& Martins, C. Nutrição e o rim (2 ed.). Rio de Janeiro: Guanabara Koogan. p44-50.

Nerbass, F. B., et al (2019). Diferenças na fosfatemia e na frequência de consumo de fontes alimentares de fósforo em pacientes em hemodiálise do sul e norte do Brasil. Brazilian Journal of Nephrology, 41(1), 83-88. https://dx.doi.org/10.1590/2175-8239-jbn-2018-0063.

Nerbass, F. B., et al (2017). Percepções de pacientes em hemodiálise sobre as restrições alimentares. Brazilian Journal of Nephrology, 39(2), 154-161. https://doi.org/10.5935/0101-2800.20170031.

Porto, R. A., Truite, M. R., Bucharles, S. E. G., \& Hauser, A. B. (2016). Hiperparatireoidismo secundário: uma complicação da Doença Renal Crônica. Rev Bras Anal Clin, 3(48):182-8.

Rodrigues, I. D., et al (2017). Relação entre consumo alimentar e ganho de peso interdialítico em doentes renais crônicos. Rev Saúde.Com, $13(01)$ : 779-85.

Santos, A. C. B., et al (2013). Associação entre qualidade de vida e estado nutricional em pacientes renais crônicos em hemodiálise. Brazilian Journal of Nephrology, 35(4), 279-288. https://dx.doi.org/10.5935/0101-2800.20130047.

Selem, S. S. C., et al (2014). Validade e reprodutibilidade de um questionário de frequência alimentar para adultos de São Paulo, Brasil. Rev Bras Epidemiol, 17(4):852-9. https://doi.org/10.1590/0102-311X00151313.

Riobó Serván, P., \& Moreno Ruiz, I. (2019). Nutrición en insuficiencia renal crónica [Nutrition in chronic kidney disease]. Nutricion hospitalaria, 36(Spec No3), 63-69. https://doi.org/10.20960/nh.02812.

Sesso, R. C., et al (2017). Inquérito Brasileiro de Diálise Crônica 2016. Brazilian Journal of Nephrology, 39(3), 261-266. https://doi.org/10.5935/01012800.20170049

Telles, C., \& Boita, E. R. F. (2015). Importância da terapia nutricional com ênfase no cálcio, fósforo e potássio no tratamento da doença renal crônica. Perspectiva, 39(145)143-154. 
Research, Society and Development, v. 10, n. 4, e54710414545, 2021

(CC BY 4.0) | ISSN 2525-3409 | DOI: http://dx.doi.org/10.33448/rsd-v10i4.14545

Universidade Estadual de Campinas - UNICAMP, Núcleo de Estudos e Pesquisas em Alimentação (NEPA). (2011). Tabela Brasileira de Composição de Alimentos (4a ed.). NEPA - UNICAMP, 2011

United States Department of Agriculture (USA). USDA Food Composition Databases. United States Department of Agriculture; 2013.

Belmar Vega, L., Galabia, E. R., Bada da Silva, J., Bentanachs González, M., Fernández Fresnedo, G., Piñera Haces, C., Palomar Fontanet, R., Ruiz San Millán, J. C., \& de Francisco, Á. (2019). Epidemiology of hyperkalemia in chronic kidney disease. Epidemiología de la hiperpotasemia en la enfermedad renal crónica. Nefrologia: publicacion oficial de la Sociedad Espanola Nefrologia,39(3), 277-286. https://doi.org/10.1016/j.nefro.2018.11.011.

Kalantar-Zadeh, K., \& Fouque, D. (2017). Nutritional Management of Chronic Kidney Disease. The New England journal of medicine, 377(18), 1765-1776. https://doi.org/10.1056/NEJMra1700312. 